\title{
Conflicted landscapes: The Kall Trail. Monitoring transformations of a Second World War heritage site using UAV-lidar remote sensing and ground truthing
} Mirjam Adam ${ }^{1, *}$, Marcel Storch ${ }^{2}$ (D) \& Christoph A. Rass ${ }^{1}$

${ }^{1}$ Modern History and Historical Migration Studies, Osnabrück University, Germany

${ }^{2}$ Institute of Computer Science, Osnabrück University, Germany

* Author for correspondence $₫$ miadam@uni-osnabrueck.de

The transformation of Second World War heritage sites is a common challenge for today's memory culture. In this project, we combine ground truthing with drone-based, high-resolution laser scanning to document recent anthropogenically and environmentally caused transformation processes, and to raise public awareness of the importance of the ever-changing conflict landscape of the 'Huertgen Forest'.

Keywords: Germany, Kall Trail, Huertgen Forest, Second World War, conflict landscapes, UAV-lidar

\section{Background}

Since 2020, historians, geoinformatics scientists and geoarchaeologists within the Interdisciplinary Working Group on Conflict Landscapes (https://www.konfliktlandschaften.uni-osnabrueck. de/idee.html) at Osnabrück University have worked on a research project that combines the concepts of layered landscapes (Saunders 2002; Saunders et al. 2013), GIS-based analyses concerning transformation processes of historical sites, remote sensing and (geo-)archaeological materiality (Saunders 2002; Rass \& Lohmeier 2011; Saunders et al. 2013; Passmore et al. 2014; Stichelbaut \& Cowley 2016; Opitz \& Herrmann 2018; Stele et al. 2021). We examine traces of the historical 'conflict landscape' (Woodward 2014; Stichelbaut \& Cowley 2016) of the Huertgen Forest in western Germany to detect and document anthropogenic and environmental transformations.

The campaign of the Huertgen Forest formed part of the advance of the US Army into Germany from September 1944 to February 1945. Nevertheless, its events were mostly disregarded by post-war research due to the focus on seemingly more prominent battles, such as the 'Battle of the Bulge'. The 'Battle of the Huertgen Forest', however, is noted today for its comprehensive attrition of the units, the severe casualties and the wrong estimations of leading military personnel concerning the battle's main objectives (Miller 1995). In this study, our research area is delimited to the Kall Trail, a critical site within the campaign that connects the villages Vossenack and Kommerscheidt across a steep gorge (Figure 1). During the campaign in November 1944, the Kall Trail served as the US Army's main supply

Received: 12 October 2021; Revised: 15 January 2022; Accepted: 18 January 2022

(C) The Author(s), 2022. Published by Cambridge University Press on behalf of Antiquity Publications Ltd. This is an Open Access article, distributed under the terms of the Creative Commons Attribution licence (https:// creativecommons.org/licenses/by/4.0/), which permits unrestricted re-use, distribution, and reproduction in any medium, provided the original work is properly cited. 


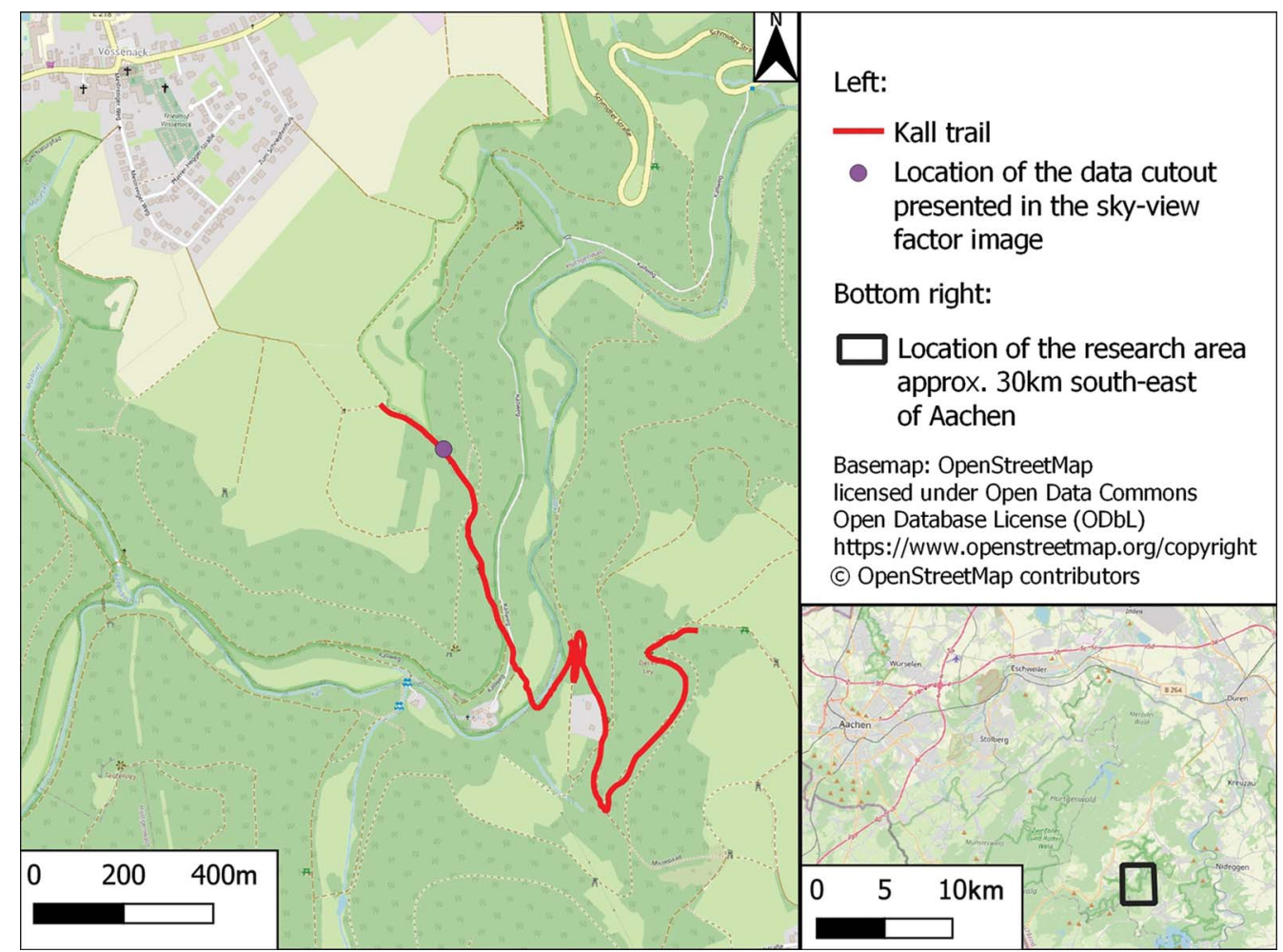

Figure 1. The course of the Kall Trail, from Vossenack to Kommerscheidt, and location of the research area (basemap by: OpenStreetMap; figure by M. Storch).

route, but it presented significant logistical challenges due to the valley's difficult terrain. Thus, the Trail became well known in historical narratives.

Until now, many dugout positions-presumably of the 28th Infantry Division-are still detectable along the Trail. Consequently, it is frequently targeted by looters who dig for historical artefacts, thereby damaging the sites extensively. Moreover, re-enactors 'replay' ground combat by occupying historical field positions, transforming them for their re-enactments, as well as digging new foxholes (Figure 2; Fings \& Möller 2016; Wöltering 2016). In causing severe damage to the archaeological evidence, new layers of landscape (Saunders 2002; Saunders et al. 2013; Passmore et al. 2014) are created, which are often mistakenly considered to be historical. Similar transformations and looting activity on former battlefields have been subject to previous scientific research and, thus, questions persist on how to approach the problem of 'disappearing' historical sites (e.g. Kok 2006).

A notable example of these transformation processes is a pit on the west side of the Kall Trail that may have originally been a foxhole associated with the conflict but has been massively transformed by re-enactors and natural erosion (Figures 2, $3 \& 4$ ). Re-enactors have presumably copied a mistakenly ascribed photograph (Schultz 1949; see https://alchetron. $\mathrm{com} / \mathrm{cdn} / \mathrm{battle-of-hrtgen-forest-06382017-f5b0-480e-9e91-2410c3518fd-resize-750.jpeg \text {) }}$ to the Huertgen Forest campaign—but which actually shows part of a US operation in 


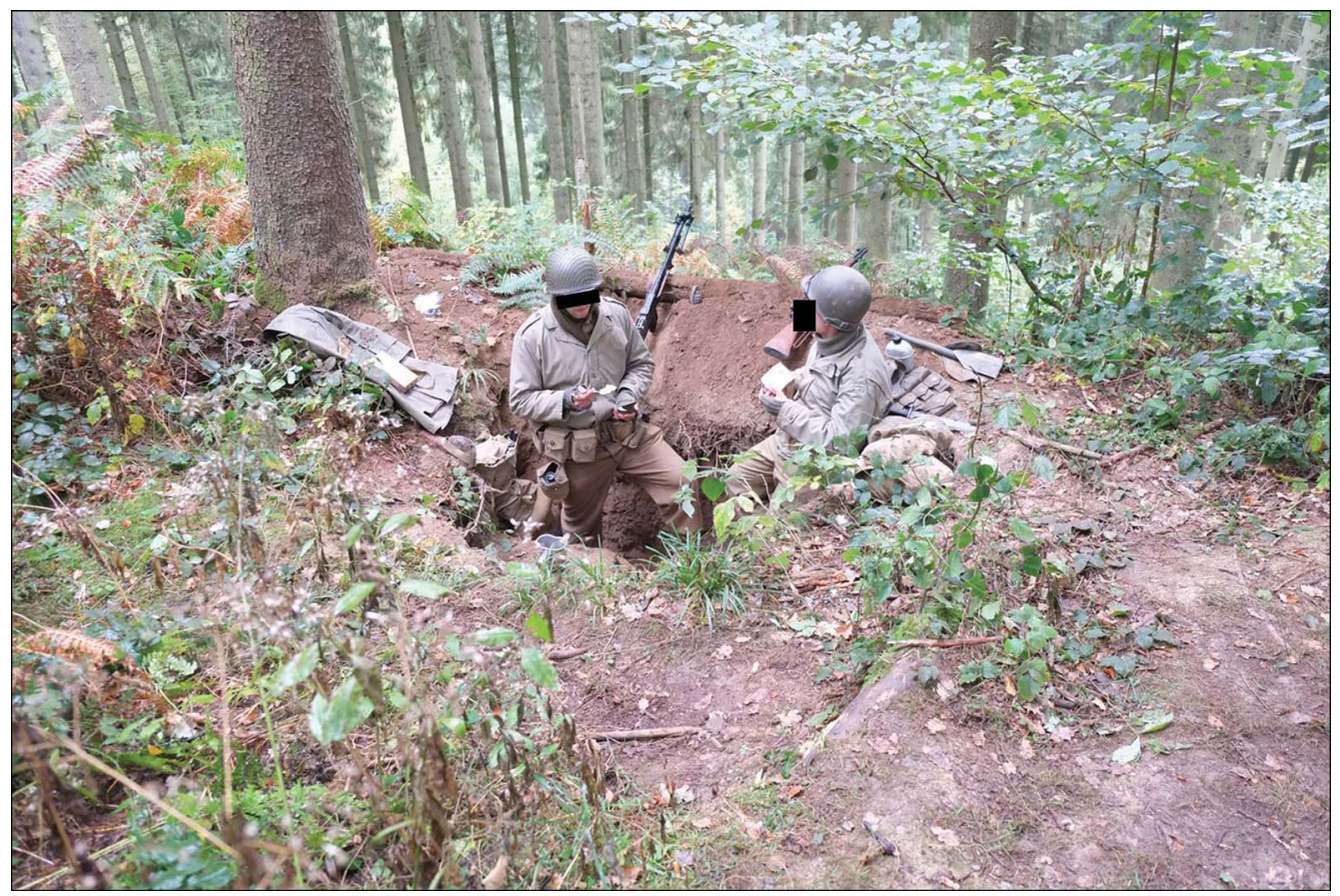

Figure 2. Dugout position transformed by re-enactors at the 'International Huertgenwald Marsch', 2016 (photograph by F. Möller).

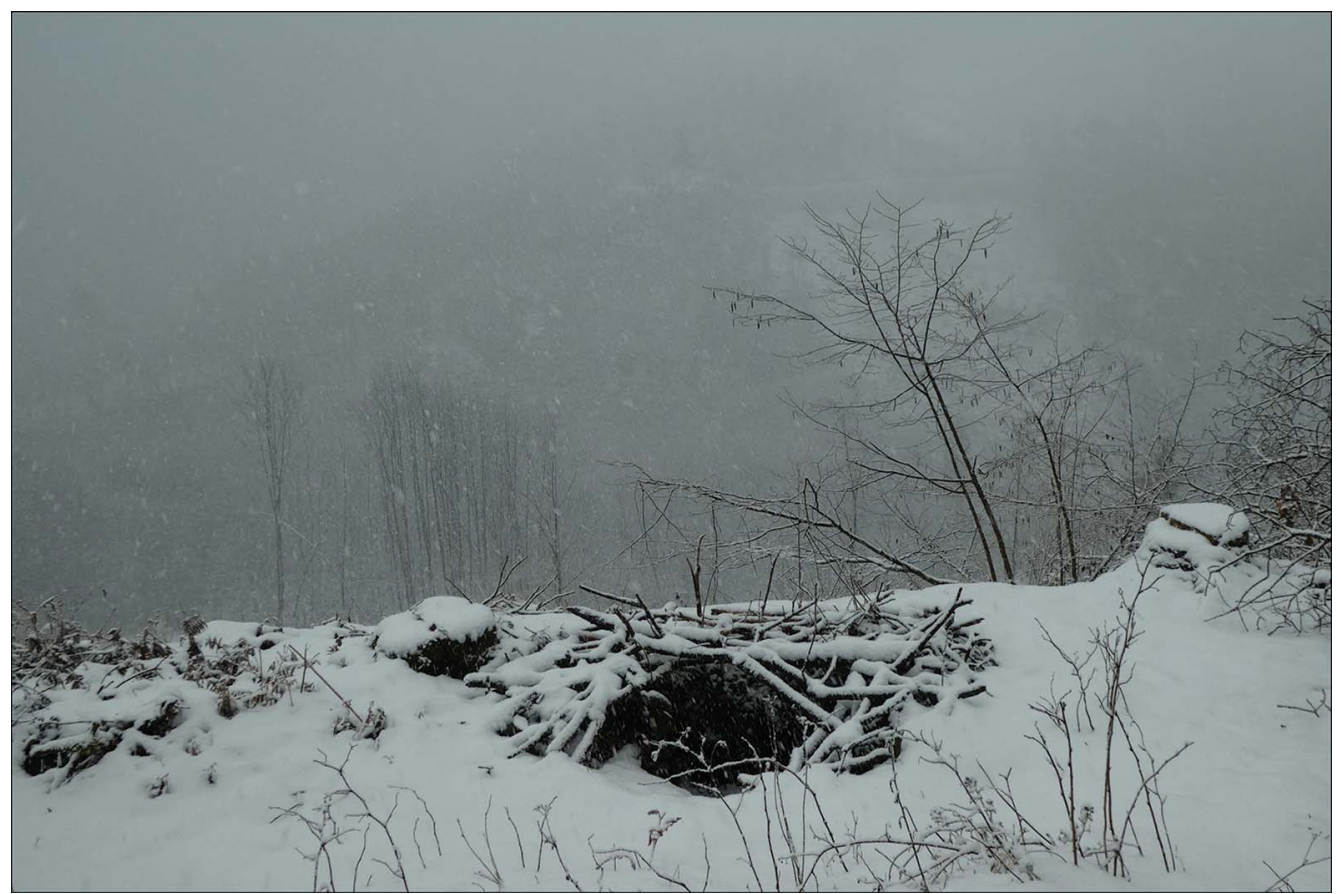

Figure 3. Pit considered to be a foxhole on the Kall Trail, February 2020 (photograph by M. Adam).

(C) The Author(s), 2022. Published by Cambridge University Press on behalf of Antiquity Publications Ltd 


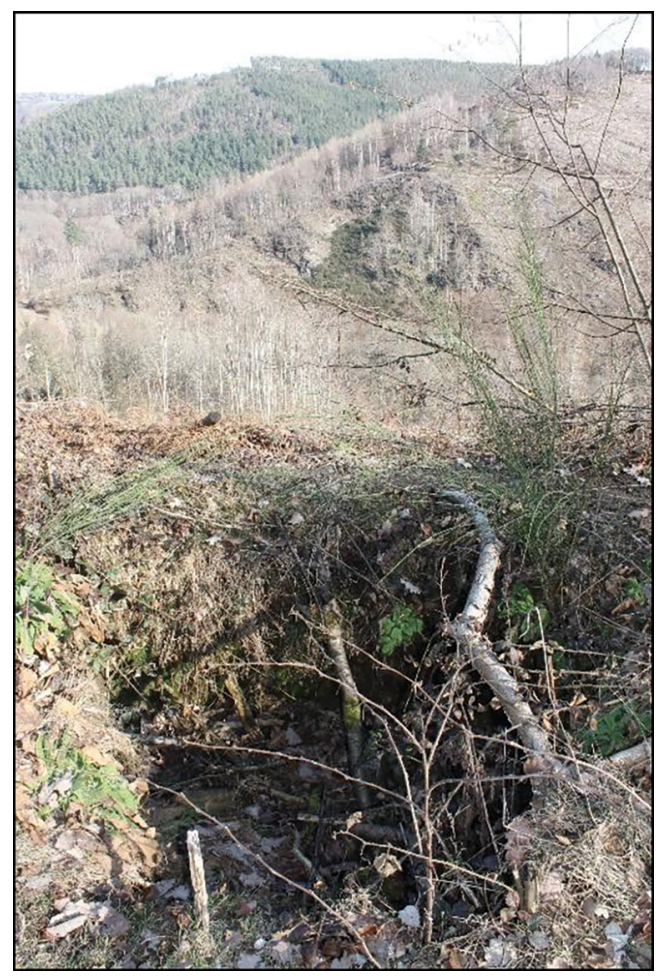

Figure 4. Same pit as shown in Figure 3, March 2021 (photograph by M. Adam).
Grezzano, Italy (1944) — to create a replica dugout position. Figures 3 and 4 show the extent of the pit's transformation regarding its changing depth and appearance, and the pace of natural overgrowth. Today, its surrounding area is also heavily transformed due to extensive deforestation and uprooting caused by storms and barkbeetle infestations in 2020 .

Consequently, several fake combat positions have appeared and have become accessible for tourists 'experiencing' the battlefield. The juxtaposition of presumably authentic historical traces and modern practices creates an ambiguous scenery that is rarely reflected upon critically. These layered transformations thus contribute to inconsistent narratives on historical events (Möller 2016; Stele et al. 2021) that miss reliable evidence, leading to inaccurate interpretations of discovered artefacts and features. Such intentionally and environmentally caused transformations destroy these unique ground monuments irretrievably.

Hence, we intend to develop a systematic, non-invasive approach to detect and document the traces of war and recent transformations as interwoven processes, using remote sensing lidar (light detection and ranging) (corresponding to Van der Schriek \& Beex 2018).

\section{Methodical approach}

Our approach in August 2020 was based on analyses of georeferenced historical disposition overlays and military aerial reconnaissance photographs. We also used intelligence reports of the US Army (NARA), pointclouds from terrestrial lidar, Digital Terrain Models (DTM) derived from governmental airborne laser scanning (ALS) and performed systematic ground truthing. The ALS data (point density of approximately 10 points $/ \mathrm{m}^{2}$ ) was acquired in April 2016 by plane (GEOportal.NRW 2020). The data, however, were insufficiently accurate to determine whether the supposed foxhole (Figures $3 \& 4$ ) —which has also been documented at least since 2016 (Figure 2; also see the arrows in Figure 5) —or other suspected anomalies in its proximity were extant during ALS data acquisition.

To address this problem, we developed our approach in August 2020 and March 2021 using high-resolution Unmanned Aerial Vehicle (UAV)-lidar, with a RIEGL miniVUX-1 UAV laser scanner mounted on a DJI Matrice 600 drone. Its spatial resolution (100 points $/ \mathrm{m}^{2}$ ) is 10 times higher than that generated from ALS. Figure 5 shows the sky-view

(C) The Author(s), 2022. Published by Cambridge University Press on behalf of Antiquity Publications Ltd 

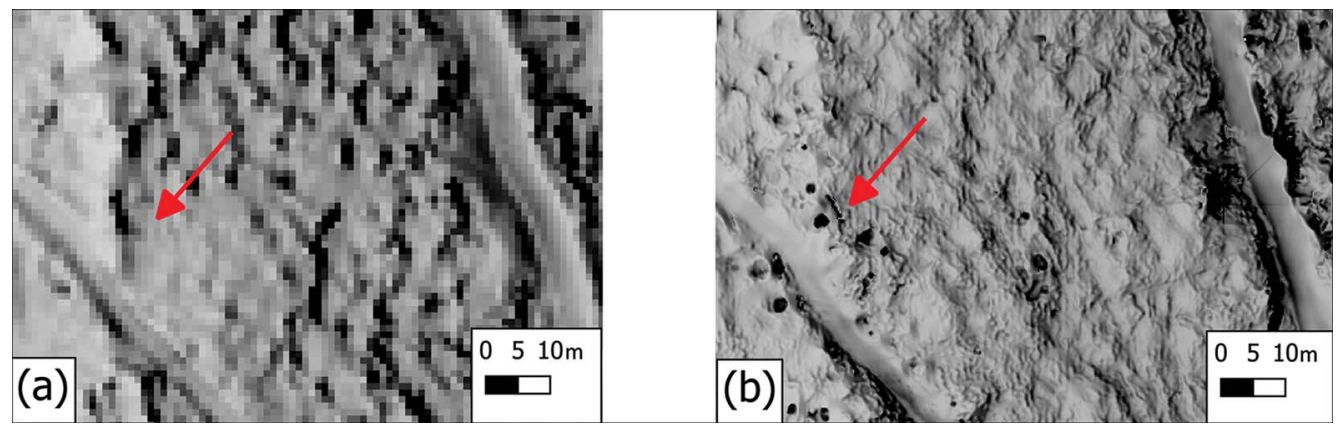

Figure 5. Discrepancy in level of detail derived from (a) airborne-lidar (ALS) and (b) UAV-lidar (data and figure by M. Storch).

factor visualisation derived from both lidar point clouds (purple dot in Figure 1). Detectable ground anomalies such as the transformed foxhole (Figures $3 \& 4$ ) and other supposed dugout positions and pits deriving from uprooted trees-all of which were confirmed by ground truthing-proved to be clearly visible in the detailed UAV-lidar data (see Figure 5).

The combination of high-resolution UAV-lidar with on-site verification enables us to identify, document and analyse systematically the specific terrain anomalies of this Second World War battlefield. This approach will facilitate future interdisciplinary analyses of diverse 'conflicted' landscapes, enabling the more efficient data acquisition and higher temporal and spatial resolution that is required to validate interpretations of historical traces and transformation processes. Accordingly, we hope to raise awareness of this important ground monument and heritage site, and to prevent it from further destruction due to thoughtless utilisation or exploitation.

\section{Acknowledgements}

We thank Andreas Stele and Thomas Jarmer for their thoughts and suggestions, and Frank Möller, Achim Konejung and Rouven Meidlinger for providing photographs and information on looting activity. We also thank Ian Spurgeon and the DPAA (Defense POW/MIA Accounting Agency) for allowing us access to historical sources.

\section{Funding statement}

Financial funding and institutional framing: Landschaftsverband Rheinland (LVR).

\section{References}

Fings, K. \& F. Möller (ed.). 2016. Hürtgenwald: Perspektiven der Erinnerung. Berlin: Metropol.

GEOportal.NRW. 2020. Available at: https://www.geoportal.nrw (accessed 4 June 2021).

KoK, R. 2006. Archaeology of the Battle of Arnhem: the significance of excavated finds as an historical source (Appendix to the Newsletter of the Society of Friends of the Airborne Museum). Ministory 98: $1-8$.
Miller, E.G. 1995. A dark and bloody ground: the Hürtgen Forest and the Roer River dams, 1944-1945. College Station: Texas A\&M University Press.

Möller, F. 2016. Erinnerungslandschaft Hürtgenwald: Kontroverse Kriegs- und Nachkriegsdeutungen 70 Jahre nach Ende der Kampfhandlungen in der Eifel. Bonn: Selbstverlag Arkum e.V.

(C) The Author(s), 2022. Published by Cambridge University Press on behalf of Antiquity Publications Ltd 
Opitz, R. \& J. Herrmann. 2018. Recent trends and long-standing problems in archaeological remote sensing. Journal of Computer Applications in Archaeology 1: 19-41. https://doi.org/10.5334/jcaa. 11

Passmore, D.G., S. Harrison \& D.C. Tunwell. 2014. Second World War conflict archaeology in the forests of north-west Europe. Antiquity 88: 1275-90. https://doi.org/10.1017/S0003598X00115455

Rass, C. \& J. Lohmeier. 2011. Transformations: post-battle processes on the Hürtgenwald battlefield. Journal of Conflict Archaeology 6: 179-99. https://doi.org/10.1179/ $157407811 X 13160762840242$

SAUnders, N.J. 2002. Excavating memories: archaeology and the Great War, 1914-2001. Antiquity 76: 101-108. https://doi.org/10.1017/S0003598X00089857

Saunders, N.J. et al. 2013. Conflict landscapes of the Soča/Isonzo Front, 1915-2013: archaeological-anthropological evaluation of the Soča Valley, Slovenia. Arheo 30: 47-66.

Schultz, P.L. 1949. The 85th Infantry Division in World War II. Washington, D.C.: Infantry Journal Press.
Stele, A., M. Schwickert \& C. Rass. 2021. The Battle of Vossenack Ridge: exploring interdisciplinary approaches for the detection of US Army field positions on a Second World War battlefield. Antiquity 95: 180-97. https://doi.org/10.15184/aqy.2020.104

Stichelbaut, B. \& D. Cowley (ed.). 2016. Conflict landscapes and archaeology from above. Farnham: Ashgate. https://doi.org/10.4324/9781315259659

VAN Der Schriek, M. \& W. BeEX. 2018. The application of lidar-based DEMs on WWII conflict sites in the Netherlands. Journal of Conflict Archaeology 12: 94-114. https://doi.org/10.1080/15740773.2017. 1440960

WöLtering, F. 2016. “Tourismusregion Zweiter Weltkrieg"? Eine kritische Situationsanalyse des Kriegstourismus zwischen Rhein, Mosel, Maas und Sauer, in K. Fings \& F. Möller (ed.) Hürtgenwald: Perspektiven der Erinnerung: 13354. Berlin: Metropol.

Woodward, R. 2014. Military landscapes: agendas and approaches for future research. Progress in Human Geography 38: 40-61. https://doi.org/10.1177/0309132513493219 